\title{
Patterns of calculated basal drag on Ice Streams B and $C_{\text {, }}$ Antarctica
}

\author{
I. M. WHILLANS \\ Byrd Polar Research Center and Department of Geological Sciences, The Ohio State University, Columbus, Ohio 43210, U.S.A. \\ C.J. VAN DER VEEN \\ Byrd Polar Research Center, The Ohio State University, Columbus, Ohio 43210, U.S.A.
}

\begin{abstract}
Patterns of strain rate and slope on the ice streams are unusual. They cannot be accounted for in the usual way as due to standing waves in ice flow over a basal obstruction to flow (such as a sticky spot). The features are studied using the force-budget technique. The conventional flow law is used, together with measurements of surface strain rate and shape of the glacier, to compute basal drag. The results for Ice Stream $\mathrm{C}$ are as expected, in that the drag varies from site to site but is directed inland, restraining the flow. The calculated drag at the base of Ice Stream B, on the other hand, is in places such that it acts to propel the glacier forward. This result is untenable. Either the conventional flow law is not applicable to Ice Stream B or there are large spatial variations in ice stiffness, perhaps associated with foliation, or both.
\end{abstract}

\section{INTRODUCTION}

Most of the drainage of the West Antarctic ice sheet is through ice streams and outlet glaciers. An understanding of the flow of these fast drainages is necessary for an evaluation of the stability of this ice sheet. Ice Stream B, in particular, is enormous. It is $500 \mathrm{~km}$ long, $50 \mathrm{~km}$ wide, $1 \mathrm{~km}$ thick and has speeds in the $1-3 \mathrm{~m} \mathrm{~d}^{-1}$ range. The surface is marked by large and closely spaced crevasses, and there are longitudinal ridges in the surface aligned with the direction of ice motion. In common with other ice streams, it is laterally bounded by nearly stagnant ice. Perhaps most striking is that the fast motion is achieved in spite of rather small driving stresses associated with the action of gravity. The processes responsible for the focusing of flow into ice streams, for their fast motion, for the longitudinal ridges and for the negative mass balance of Ice Stream B (Whillans and Bindschadler, 1988) are not understood.

Key to understanding the mechanics controling these fast-moving glaciers is a determination of the distribution of stresses acting upon them. All glaciers are driven by a component of gravity and this action is accurately described by the driving stress. The driving stress involves the product of surface slope and ice thickness, and is readily calculated. The reactions are due to friction at the bed and sides, and tension or compression up- and down-flow. The assessment of these reactive effects is usually not straightforward.

The reactive or resistive stresses can be calculated using measured surface strain rates. A constitutive relation (flow law) is used with these strain rates to calculate the corresponding stresses. These stresses describe the forces acting on vertical faces of a column through the ice. Allowance can be made for how the stresses and strain rates vary with depth. The basal drag is calculated as that necessary for the sum of all forces on the column to balance.

Such calculations have been performed at a number of sites. Rutford Ice Stream has been studied by Frolich and Doake (1988). These authors used an along-flowline integrated version of force budget and find that basal drag (the $x$-derivative of the upper curve in their figure 3 ) is the prime restraint to motion and that it varies alongglacier by large amounts. MacAyeal and others (1987) studied the forces on a box that includes Crary Ice Rise in the Ross Ice Shelf and estimated that the resistance generated by the ice rise accounts for about half the backpressure force on Ice Streams A and B. For Storglaciären, Sweden, Hooke and others (1989) calculated basal drag over a basin and riegel for periods of slow and fast ice motion. During high-speed events, the friction is reduced over the basin and is more concentrated at the riegel, presumably due to ponding of subglacial water in the basin. The present authors have studied Byrd Glacier, an outlet glacier of the East Antarctic ice sheet (Whillans and others, 1989), the inland ice of West Antarctica along the Byrd Station Strain Network (Van der Veen and Whillans, 1989b) and the inland ice of Greenland (Van der Veen and Whillans, 1990). In all of these cases, basal drag is the most important restraint on grounded ice and is concentrated at isolated "sticky spots" about $10 \mathrm{~km}$ apart. On floating ice, where basal drag is zero, other restraints are more important. These studies indicate that the force-budget technique is very useful in assessing the mechanics of glacial motion. 
There is special interest in the force budgets of Ice Streams B and C. The dynamics of ice streams are largely not understood. Moreover, these neighboring ice streams have radically different behavior. Ice Stream B is moving quickly and draining its catchment faster that it is being replenished (Whillans and Bindschadler, 1988). Ice Stream C, in contrast, has virtually stopped (McDonald and Whillans, 1988; Thomas and others, 1988) and is thickening at its accumulation rate. The mean driving stress for both ice streams is about equal and so the contrast in behavior must be due to the mechanics controling these two ice streams.

The mechanics are probably closely linked with the distribution and behavior of basal lubrication. A possibility is suggested by the results of active seismic work on Ice Stream B. These indicate the presence of a very porous debris layer up to $12 \mathrm{~m}$ thick at the base of the ice stream (Blankenship and others, 1986). Alley and others (1986) suggested that this layer may be continuous and deforming. If so, this layer controls the motion of the ice stream and basal drag should be unlike that under inland ice, where it is concentrated at basal highs (Van der Veen and Whillans, 1989b); under Ice Stream B it should be small with little spatial variation.

It was with a view toward calculating the basal and lateral drags and their local variabilities that strain grids were established near the centers of Ice Streams B and C.

\section{MEASUREMENTS}

The strain grids consist of three ranks of stations approximately $1 \mathrm{~km}$ apart, arranged along the flow direction. Each rank has a letter name $(\mathrm{A}, \mathrm{B}$ and $\mathrm{C}$ for the grid on Ice Stream B, and F, G and H for that on Ice Stream C), and along each rank, stations are numbered. The stations are spaced about $1 \mathrm{~km}$ apart and form a nearly regular grid. Figure 1 shows the locations and Figure 2 shows the forms of the strain grids.

The grid on Ice Stream C was surveyed for positions during the austral summers of 1983-84 and 1985-86; that on Ice Stream B was measured three times (1983-84,

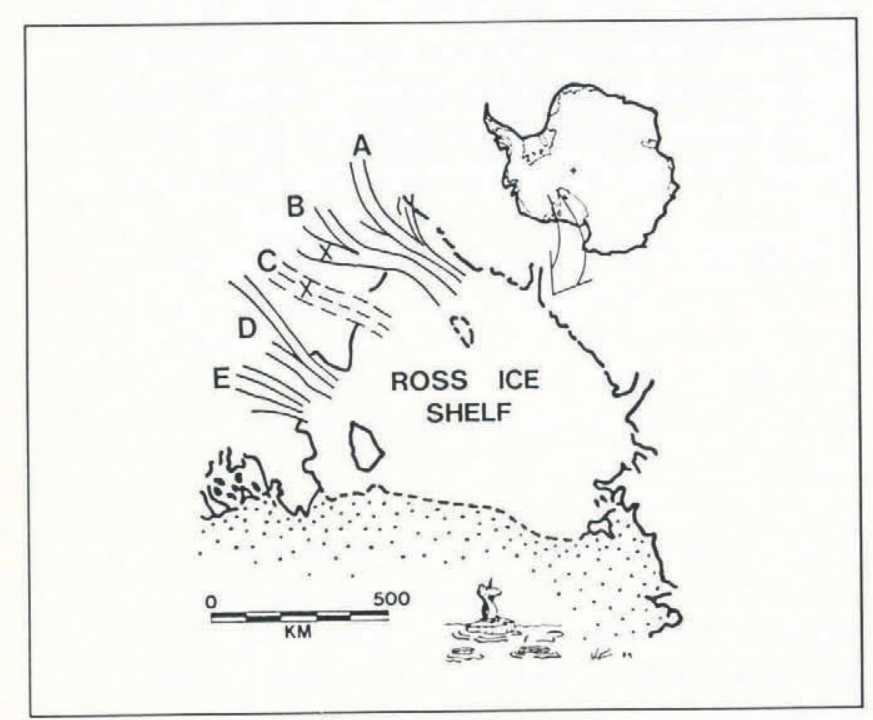

Fig. 1. Location map.

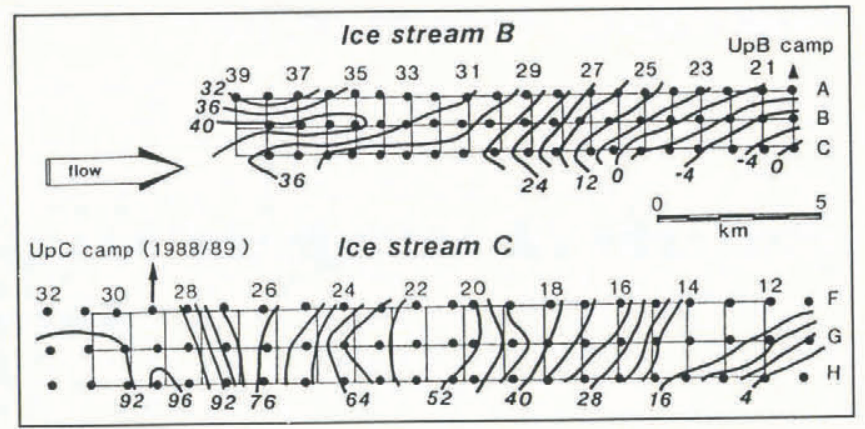

Fig. 2. Map view of arrangement of measurement stations in strain grids (interval for relative elevation is $4 \mathrm{~m}$ ).

1984-85 and 1985-86) and strain rates derived from the first and last surveys are used here.

The primary surveying technique is distance measurement using AGA model 112 Geodimeters. These are accurate to about $0.01 \mathrm{~m}$ over the distances involved, which translates to a precision in strain rate of about $1 \%$ of typical strain rates. Both Geodimeter and the retrodirective prisms mount directly on the steel conduit poles (inside diameter, $25 \mathrm{~mm}$ ) used as movement markers. In the field, the data for each surveyed quadrilateral are checked for internal consistency so as to identify major measurement errors. Later, the data are used in a least-squares adjustment to calculate the coordinates of each station. Slope corrections have little effect on strain rates and were not made.

At least two stations in each grid are also TRANSIT satellite-tracking stations (B33 and the UpB camp on Ice Stream B and G12 and G28 on Ice Stream C). This allows the surveys to be tied to an Earth-based frame of reference. However, this issue is not important to the present work because strain rates are independent of translation and rotation rates.

Relative elevations are obtained by pressure altimetry. This is a very efficient technique. Large, sudden, secular pressure changes are rare in central Antarctica. If they do occur and cause poor closure of a survey loop, the data from that loop are rejected and the loop is repeated. The relative elevations are accurate to about $2 \mathrm{~m}$; this translates to slope errors of 0.002 and driving-stress errors of $20 \mathrm{kPa}$. The grid on Ice Stream B has been surveyed twice for relative elevation and that on Ice Stream $\mathrm{C}$ once.

No angle measurements are used. Theodolite work is time consuming, requires setting up a tripod on the unstable snow and is, ordinarily, less precise than the distance measurements. Sun shots were made but the technique is less precise than the TRANSIT technique for determining azimuths.

\section{FORGE BUDGET}

The primary product of the force-budget calculations presented here is basal drag in the $x$-direction, $\tau_{\mathrm{b} x}$. The $x$ axis is taken along the long axis of the strain grid, horizontal and positive approximately down flow (actually $4^{\circ}$ anti-clockwise from the mean flow direction on Ice Stream B, and less well-defined for Ice Stream C 
because of its extremely slow speed). The $y$-axis is horizontal and perpendicular to the $x$-axis. Basal drag is the calculated residual when the action, or driving stress, $\tau_{\mathrm{d} x}$, is corrected for the viscous forces acting on vertical faces of a column through the ice thickness:

$$
\tau_{\mathrm{b} x}=\tau_{\mathrm{d} x}+\frac{\partial}{\partial x}\left(H \bar{R}_{x x}\right)+\frac{\partial}{\partial y}\left(H \bar{R}_{x y}\right) .
$$

In this, ice thickness is represented by $H$, and $\bar{R}_{x x}$ and $\bar{R}_{x y}$ represent two components of the depth-averaged resistive stress. Resistive stresses are linked to deviatoric stresses, $\sigma_{i j}^{\prime}$, as follows (Van der Veen and Whillans, 1989a):

$$
\begin{aligned}
& R_{x x}=2 \sigma_{x x}^{\prime}+\sigma_{y y}^{\prime} \\
& R_{x y}=\sigma_{x y}^{\prime}
\end{aligned}
$$

and deviatoric stresses are, in turn, related to strain rates $\left(\dot{\epsilon}_{i j}\right)$ through the constitutive relation. The conventional version (e.g. Hooke, 1981) is used here (written in inverse form):

$$
\begin{aligned}
\sigma_{i j}^{\prime} & =B \dot{\epsilon}_{\mathrm{e}}^{\frac{1}{n}-1} \dot{\epsilon}_{i j} \\
\dot{\epsilon}_{\mathrm{e}}^{2} & =\frac{1}{2} \dot{\epsilon}_{i j} \dot{\epsilon}_{i j} .
\end{aligned}
$$

The vertically averaged resistive stress, $\bar{R}_{x x}$, can then be calculated from

$$
\bar{R}_{x x}=\frac{1}{H} \int B \dot{\epsilon}_{\mathrm{e}}^{\frac{1}{n}-1}\left(2 \dot{\epsilon}_{x x}+\dot{\epsilon}_{y y}\right) \mathrm{d} z
$$

in which the integral is taken over the ice thickness.

If the depth variation in ice velocity over the ice thickness may be taken to be small, surface values may be used for strain rates throughout the ice thickness. In that case, the above expression may be simplified to

$$
\bar{R}_{x x}=\bar{B} \dot{\epsilon}_{\mathrm{e}}^{\frac{1}{n}-1}\left[2 \dot{\epsilon}_{x x}+\dot{\epsilon}_{y y}\right]
$$

where

$$
\bar{B}=\frac{1}{H} \int B \mathrm{~d} z
$$

is the depth-averaged rate factor, and strain rates at the surface are used.

The other resistive stresses needed in the force-budget calculation can be estimated from expressions similar to Equation (5) (cf. Van der Veen and Whillans, 1989a).

This is the plug- or block-flow model as used in the simple model of Whillans and others (1989). In this model, there is no downward stepping involved, contrary to the full force-budget technique (Van der Veen and Whillans, 1989a) which starts at the surface and calculates velocities and stresses at depth by progressing downward. So there are no problems with the mathematical or numerical instabilities often encountered in inverse calculations.

The driving stress follows the usual definition:

$$
\tau_{\mathrm{d} x}=-\rho_{\mathrm{i}} g H \frac{\partial h}{\partial x}
$$

in which $h$ represents surface elevation, $\rho_{\mathrm{i}}$ is ice density and $g$ is acceleration due to gravity. This definition requires no spatial averaging and the driving stress is calculated over minimum centered intervals $(2 \mathrm{~km})$.
The component of basal drag in the cross-flow $y$ direction, $\tau_{\text {by }}$, can also be calculated, but discussion in this contribution is concerned only with the along-flow component, $\tau_{\mathrm{b} x}$.

In the equations above, bridging effects have been neglected. Bridging effects arise when vertical normal stresses differ from lithostatic ones so that parts of the glacier rest more lightly on the bed than other parts, much like the arch and abutments of a real bridge. Only under extreme circumstances do these effects significantly influence the horizontal budget of forces. Bridging effects are unimportant along the Byrd Station Strain Network (Van der Veen and Whillans, 1989b) and are expected to be unimportant here. Therefore, as a start, they are neglected, but the issue is discussed below.

The depth-averaged value of the rate factor used is $536 \mathrm{kPa}^{\frac{1}{3}}$, based on measured temperatures in a borehole near the UpB camp on Ice Stream B (Engelhardt and others, 1990) and the rate factors recommended by Hooke (1981). This value of $536 \mathrm{kPa} \mathrm{a}^{\frac{1}{3}}$ corresponds to a temperature of $-18^{\circ} \mathrm{C}$ and it compares well with values of $490-640 \mathrm{kPa} \mathrm{a}^{\frac{1}{3}}$ given in Paterson and Budd (1982).

\section{RESULTS}

The primary results are depicted in Figures 3 and 4 . At the top of each figure is the driving stress, obtained from measurements of the geometry (surface slope and thickness). The next two curves are the viscous terms. These are sensitive to the rate factor in the flow law and to depth variations in strain rates. The solid bottom curve shows the sum of those above and it is the basal drag.

As ordinarily expected, the basal drag on Ice Stream $\mathrm{C}$ is positive everywhere and opposes the motion of the ice stream towards the sea (Fig. 4). These results are like those obtained for Storglaciären (Hooke and others,

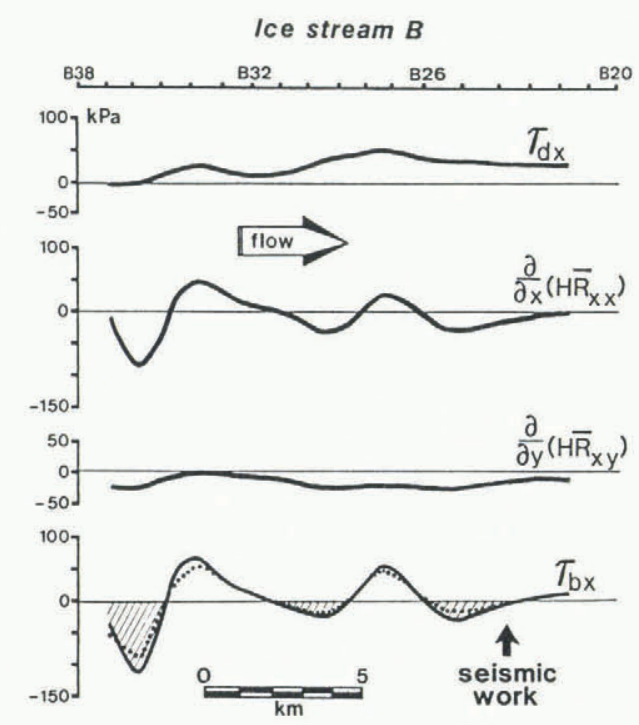

Fig. 3. Major terms in calculation of basal drag for Ice Stream B. From the top are station location, driving stress, along-flow increase in tension, across-flow increase in lateral drag, and basal drag (sum of the three curves above). The dotted line is basal drag with along-flow bridging effects included. Shading indicates where basal drag is negative. 


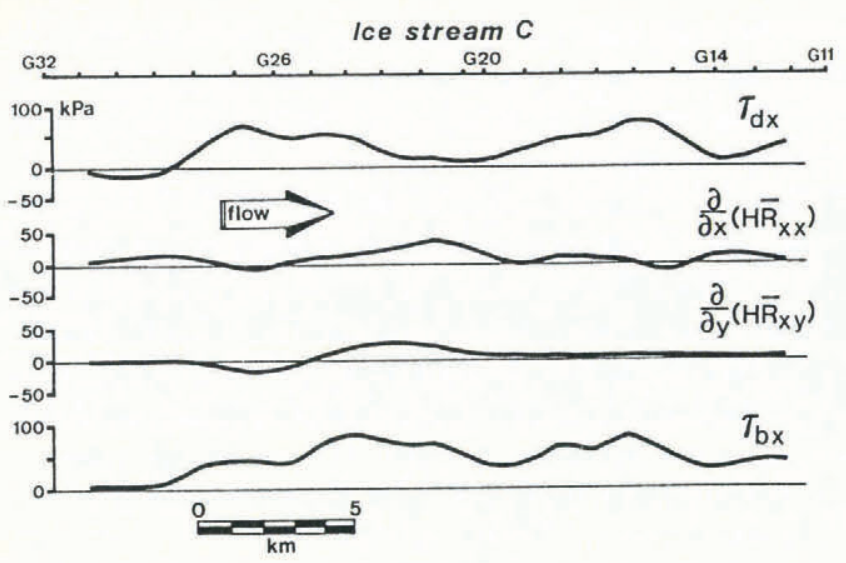

Fig. 4. As Figure 3, but for Ice Stream C.

1989), for the Byrd Station Strain Network (Van der Veen and Whillans, 1989b), for Byrd Glacier (Whillans and others, 1989) and for Dye 3 (Van der Veen and Whillans, 1990).

The results from Ice Stream B are surprising (Fig. 3). The basal drag is negative in several places. This is difficult to understand and is completely unexpected. If valid, it indicates that some process at the base acts to propel the glacier forward, instead of resisting motion.

The most immediate thought is that at least one of the assumptions made must be invalid. Specifically, one may wonder if the rate factor selected for the flow law is wrong. This can easily account for the calculated negative drags near stations B29 and B25. However, the most negative values for basal drag occur where the driving stress is near zero, and a change in rate factor would merely change the value of basal drag, not its negative sign.

\section{ORIGIN OF THE REVERSE BASAL DRAG RESULT}

To investigate the origin of the negative basal drag, consider the balance equation for the $x$-direction written in terms of strain rates, rather than stresses:

$$
\begin{aligned}
\tau_{\mathrm{b} x}=\tau_{\mathrm{d} x} & +\bar{B} H \dot{\epsilon}_{\mathrm{e}}^{\frac{1}{n}-1} \frac{\partial}{\partial x}\left(2 \dot{\epsilon}_{x x}+\dot{\epsilon}_{y y}\right) \\
& +\bar{B} H\left(2 \dot{\epsilon}_{x x}+\dot{\epsilon}_{y y}\right)\left(\frac{1}{n}-1\right) \dot{\epsilon}_{\mathrm{e}}^{\frac{1}{n}-2} \frac{\partial}{\partial x}\left(\dot{\epsilon}_{\mathrm{e}}\right) \\
& +\bar{B} H \dot{\epsilon}_{\mathrm{e}}^{\frac{1}{n}-1} \frac{\partial}{\partial y}\left(\dot{\epsilon}_{x y}\right) \\
& +\bar{B} H \dot{\epsilon}_{x y}\left(\frac{1}{n}-1\right) \dot{\epsilon}_{\mathrm{e}}^{\frac{1}{n}-2} \frac{\partial}{\partial y}\left(\dot{\epsilon}_{\mathrm{e}}\right)
\end{aligned}
$$

assuming constant thickness and mean rate factor. The usual definition of strain rate applies:

$$
\dot{\epsilon}_{i j}=\frac{1}{2}\left(\frac{\partial u_{i}}{\partial x_{j}}+\frac{\partial u_{j}}{\partial x_{i}}\right) \quad i, j=x, y
$$

in which $x_{x}=x, x_{y}=y$. Figures 5 and 6 show all the steps involved in calculating the viscous terms. These steps should be self-explanatory on consulting Equation (8).
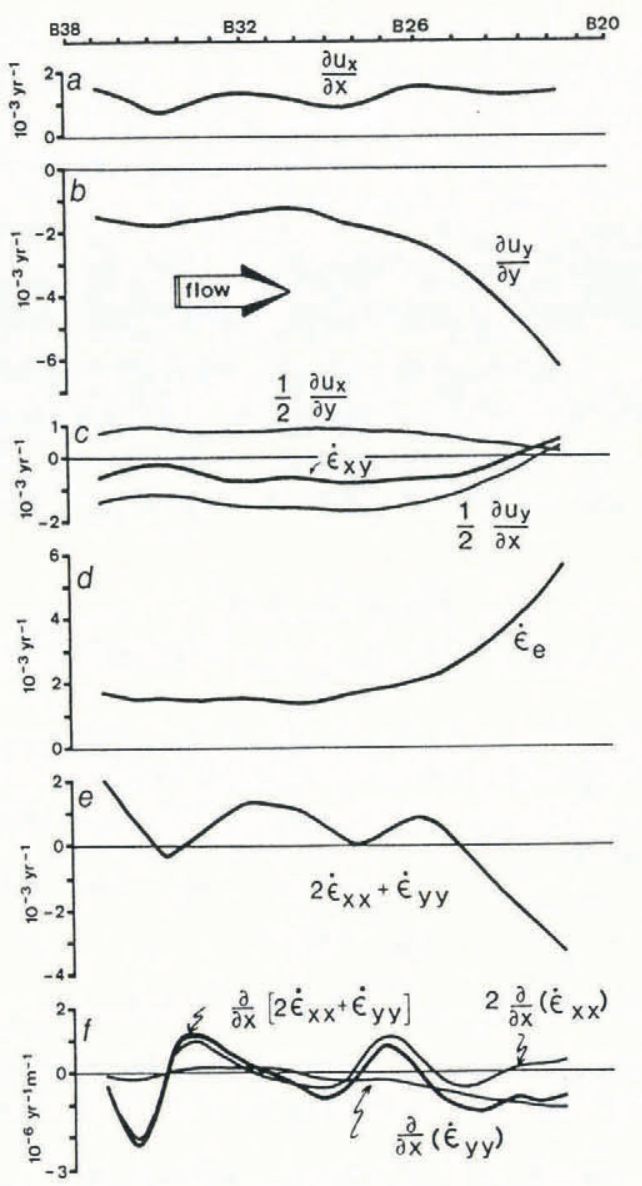

Fig. 5. First steps in calculation of basal drag for Ice Stream $B$. The relevance of the curves can be understood on consulting Equation (8).
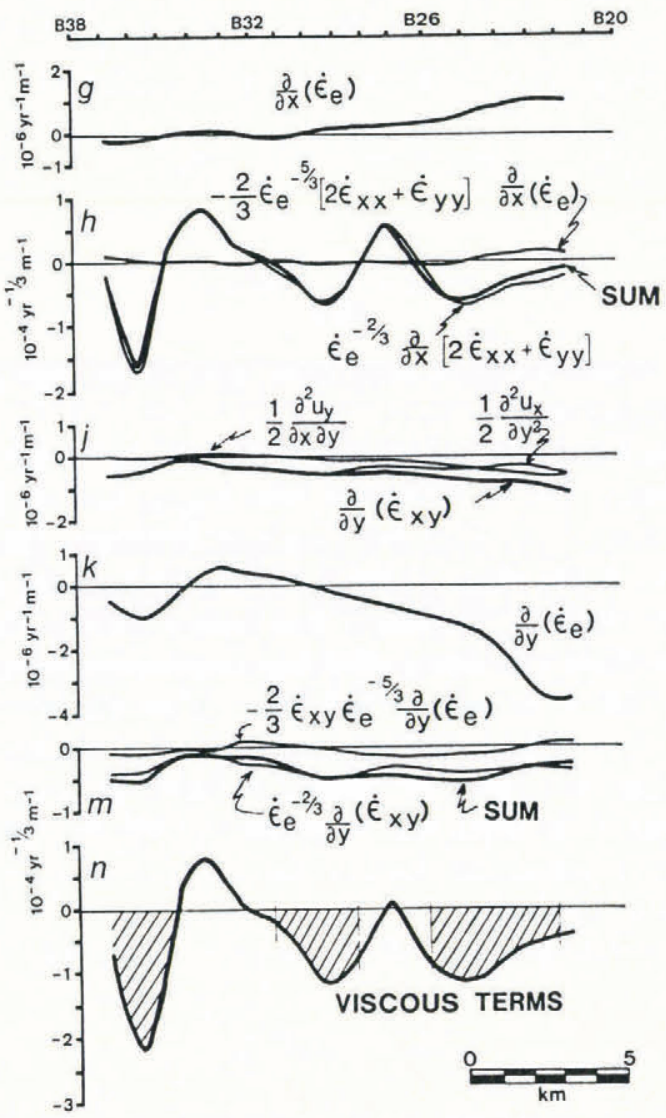

Fig. 6. Remaining steps in calculation of basal drag for Ice Stream B. In panel $n$, shading corresponds to regions of negative basal drag. 
Two of the velocity gradients contribute most to the negative basal drag (Fig. 5). The major contributor is the longitudinal strain-rate gradient, $\partial \dot{\epsilon}_{x x} / \partial x$, or $\partial^{2} u_{x} / \partial x^{2}$ (panel f). The region between stations B38 and B36 is under greater tension than that between stations B36 and B34 (panel a). The associated net up-glacial force is balanced in the equation by a down-glacially directed basal drag. A secondary contribution is due to the gradient in lateral shear, $\partial^{2} u_{x} / \partial y^{2}$, which is part of $\partial \dot{\epsilon}_{x y} / \partial y$ (panel $\mathrm{j}$ in Figure 6). This is important everywhere except near station B34. It arises because of stronger negative shear between the A and B ranks of stations than between the $\mathrm{B}$ and $\mathrm{C}$ ranks. The gradient is probably due to the progressively diminishing effect of the ice-stream side: the A rank is closest to the southern margin and the $\mathrm{C}$ rank nearest to the ice-stream center. Gradients in lateral shearing, which affect $\partial\left(H R_{x y}\right) / \partial y$ are only about one-third as important as gradients in longitudinal tension, $\partial\left(H R_{x x}\right) / \partial x$ (Fig. 3). That is, the calculated negative drags derive mainly from downglacier reductions in tension and, secondly, from gradients in lateral shear rate.

The curves in the second and third panels of Figure 3 are the same as the curves labeled "sum" in panels $h$ and n, respectively, of Figure 6, but multiplied by ice thickness and the rate factor.

The value of the exponent, $n$, in the flow law (taken equal to three) has little effect on the calculated basal drag. It could be important because the effective strain rate is raised to a power involving $n$. However, the effective strain rate is nearly constant in the region of negative basal drag, both along flow (Fig. 6, panel g) and transverse (Fig. 6, panel k). The roles of gradients in effective strain rate are shown in panels $\mathrm{h}$ and $\mathrm{m}$ of Figure 6 . Their effects are small.

\section{REJEGTED INTERPRETATIONS FOR THE GRID ON IGE STREAM B}

The result shown in Figure 3 is difficult to understand. Various potential explanations for the calculated pattern in basal drag are investigated in this section.

\section{Data errors}

\section{(a) Strain rates}

The strain grid on Ice Stream B has been measured three times. This means that two sets of independent strain rates can be calculated. These two sets are nearly identical except that the strain-rate pattern migrates with respect to the stations, and is consistent with the pattern being fixed with respect to the bed. This repeatability in the strain rates is a strong indication that there are no survey blunders.

Inspection of the residuals of the least-squares adjustment of measured distances to calculate the coordinates of the stations also shows no unusual mismatch of any of the surveys. Thus, there does not appear to be any mistake in surveying.

Slope corrections were not made. However, the slope is so small that the corrections are also small. Moreover, the corrections would be common to all three surveys and would nearly completely cancel when the survey results are differenced to obtain strain rates and strain-rate gradients. A very small and negligible correction arises if the slope changes between surveys for strain rate.

No corrections are made to account for the movement of the stakes to new positions. On some glaciers, velocities and velocity gradients are so large that the strain rate between two stations changes in an important way during the measurement epoch. This is not a problem here.

\section{(b) Surface slope}

Two independent surveys for relative elevation were made by different workers (I. M. Whillans in 1983-84 and $M$. Strobel in 1984-85) using the same technique. The results were identical to well within the measurement errors quoted above and so, again, mistakes can be discounted. (The measurements are not precise enough to detect small time changes in relative elevation.) Moreover, the qualitative pattern of surface slope conforms with casual observation by field workers. The sites of upward convexities were confirmed during the EDM work when line-of-sight problems were encountered and intermediate stations (not shown in Figure 2) had to be established.

\section{(c) Ice thickness}

This is one of the least critical measurements and, for simplicity, the thickness in the calculation is held constant at $1000 \mathrm{~m}$. In fact, it varies between 1020 and $1070 \mathrm{~m}$ along the center line and between 1020 and $1120 \mathrm{~m}$ over the entire grid (personal communication from $\mathrm{S}$. Shabtaie) but this variation has a very minor effect on the calculation. The accuracy of thickness measurement is about 1\% (Shabtaie and Bentley, 1988). Other workers obtained very comparable values (Rose, 1979; personal communication from R. Moore, 1989).

The effective thickness for ice mechanics is less than the measured thickness. Firn has little strength and transmits stresses poorly and so only the ice part of the glacier should be used in calculating horizontal forces. The firn is about $30 \mathrm{~m}$ thick (Alley and Bentley, 1988); this is very small and the effect may be neglected. Secondly, the upper part of the glacier is crevassed. This must weaken the ice so that the upper part does not participate fully in stress transmission in the direction perpendicular to crevasse orientation. The depth of crevasses is not known but it is estimated at $60 \mathrm{~m}$. Provided the crevasse density is uniform, the effective thickness for the viscous terms should be reduced by their depth but this effect is too small to solve the problem of the negative basal drag. Finally, the driving stress needs to be reduced by a very small amount to allow for reduced densities in the firn. This, too, is negligible.

\section{Errors in finite differencing}

Derivatives are calculated in determining surface slope, strain rate and strain-rate gradient. It is most convenient if all are calculated for the same points. The data are available at the survey stations, which are spaced only nominally at $1000 \mathrm{~m}$ intervals (Fig. 2). To solve this problem, a gridding scheme is used to compute the needed quantities at regularly spaced sites. 
The gridding uses a cubic-spline interpolation for each rank of stations. Because the measured grid is only three ranks wide, and because deviations from a straight line are small for each row of poles, data for each rank were gridded separately. No adjustment, such as a leastsquares scheme, is applied. The scheme used for gridding is not critical; calculations with ungridded data using uncentered differences yield basically the same results.

Finite-differencing tends to produce gradients that are too close to zero. The problem here is that the gradients are too large. Derivatives in the $x$-direction are taken using data from the B line of stations only, whereas derivatives in the $y$-direction use data from stations arranged in the transverse direction. Gradients are computed over the shortest valid distances. In the case of simple second derivatives, namely $\partial^{2} / \partial x^{2}$ and $\partial^{2} / \partial y^{2}$, data from three stations in a longitudinal or transverse line are used. Cross second derivatives, $\partial^{2} / \partial x \partial y$, are calculated using data from four stations at the corners of a $2 \mathrm{~km}$ by $2 \mathrm{~km}$ box centered on the calculation point. Thus, cross double gradients represent averages over a larger area than simple second derivatives. For this reason, fluctuations in cross derivatives should be more muted than fluctuations in simple second derivatives. This mixing of regions over which derivatives are calculated could be a problem in certain applications. In this case, it is not a problem because the role of cross gradients is very small, much smaller than is due to the larger region for calculation. Of course, derivatives could be calculated over greater distances. This would smooth the fluctuations in the calculated results.

\section{Depth variation in strain rates}

The simple calculations presented here are based on the assumption that the ice velocities, and hence horizontal strain rates, are independent of depth. For Ice Stream B, this appears to be a reasonable first assumption. The measured temperature at the base of the glacier is close to the pressure-melting temperature (Engelhardt and others, 1990), so that basal sliding is likely to occur. In fact, the large velocities $\left(450 \mathrm{~m}\right.$ year $^{-1}$ at UpB camp; Whillans and others, 1987) cannot be explained by shear deformation of the ice. The ice motion must be almost entirely due to basal sliding or, perhaps, as argued by Alley and others (1986), to deformation within the subglacial layer of till. In either case, the variation in velocity over the entire depth of the ice is apt to be small.

Nevertheless, strain rates and stresses can vary with depth. However, because we have taken deep layers to be warm and weak, the values of strain rate at depth are not very relevant to the calculation of force balance. Even quite different strain rates at greater depth are caused by small stresses, which have little effect on the total balance of forces. In effect, the upper part of the glacier is a stress guide. The measured strain rates relate to this upper, stress-bearing part.

It is possible to compute strain rates at depth and the associated stresses. Balise and Raymond (1985, fig. 2) and Whillans and Johnsen (1983, figs 4 and 5) calculated depth changes in strain rates using linear-viscous models by solving the biharmonic equation for flow variations. In fact, Whillans and Johnsen found that strain-rate fluctuations even have the opposite sign at depth than at the surface. It is also possible to use the fuller forcebalance technique to compute strain rates at depth, as was done for the Byrd Station Strain Network (Van der Veen and Whillans, 1989b). However, because of the stress-guide effect, such calculations would not be able to account for the anomaly of the negative drag near station B36.

\section{Basal debris flows}

Perhaps the calculated basal drags are real and there are indeed places where the glacier is being dragged forward. Subglacial debris may be traveling faster than the overlying ice and pulling it along.

The basic problem with this interpretation is that unreasonably large pressure gradients are required to drive the debris flow. Assuming a Newtonian viscosity of $450 \mathrm{Pas}$ (as observed for mud flows; Johnson, 1970), pressure gradients in excess of $30 \mathrm{kPa} \mathrm{m}^{-1}$ are needed to obtain negative values of drag at the till-ice interface. Alley and others (1986) and Boulton and Hindmarsh (1987) proposed viscosities for subglacial debris that are about $10^{7}$ times larger than Johnson's. Such viscosities make till jets even less probable.

\section{Disturbance to strain rate by crevasses}

In crevassed ice, strain rates may be expected to be smaller than average within inter-crevasse blocks, and larger than average across crevasses. Perhaps the measured strain rates contain noise due to the opening of crevasses beneath the surface.

The region under the grid is crevassed. These crevasses have been detected by short-pulse radar (personal communication from S. Shabtaie) and, indeed, some could be heard opening while in the field. The strain grid is routed especially to avoid open crevasses but this only means that the crevasses are safely buried. Where exposed, the crevasses are spaced at $100-500 \mathrm{~m}$ (Vornberger and Whillans, 1990) and this corresponds with the spacing of buried crevasses (personal communication from S. Shabtaie). This spacing should also be the wavelength of spatial variations in the strain rates due to crevasses.

The most anomalous region extends from station B38 to $\mathrm{B} 36$, a distance of $2000 \mathrm{~m}$. This is much longer than crevasse spacing and so strain-rate noise due to crevasses may be discounted.

\section{Stresses on a sloping bed}

Not all resistance to flow is due to traction. For example, there can be resistance if the bed slopes so as to block flow with longitudinal compression. Other possibilities arise from tension at a lee side or lateral traction on a cross slope. Thus, it is possible for the basal traction to be negative but for the overall basal resistance to flow to be positive.

The basal drag used here is defined to include all basal resistances (Van der Veen and Whillans, 1989a, equation (9)). It is the net effect of traction on a sloping bed and other extra-lithostatic stresses at the bed. The basal drag 
thus describes the net effect of the bed on the glacier and it should oppose the motion of the glacier.

\section{Horizontal gradients in firn thickness}

The calculation of driving stress assumes that horizontal gradients in density may be neglected. Most particularly, there could be changes in firn density and thickness. Such gradients could arise if part of the strain grid is a raft. A raft is a body of inland ice that has been incorporated into the ice stream but is little deformed (Whillans and others, 1987; Bindschadler and others, 1988). Its density profile would be more like that of slow-flowing inland ice, whereas the neighboring firn has been affected by the extreme strains of ice-stream flow and is denser.

Suppose that the firn at station B35 is especially thick. This could be because part of the topographic ridge leading to station B35 is a raft. Compressing the firn at station B35 to ice-stream densities would lead to large calculated surface slope and driving stress for station B36 (and the opposite for station B34). To remove the basal drag anomaly at station B36, an increase in driving stress of $115 \mathrm{kPa}$ is needed. This corresponds to an increase in density-corrected surface slope of 0.013. Slopes are calculated over distances of $2000 \mathrm{~m}$, so the firn at station B35 would need to be anomalously thick by $26 \mathrm{~m}$.

Alley and Bentley (1988) measured density profiles in both types of ice. They studied the firn of Ice Stream B, near station A21, and the firn at the top of inter-stream ridge $\mathrm{B} / \mathrm{C}, 50 \mathrm{~km}$ to the north. These can be considered profiles for ice affected (at station A21) and unaffected (at ridge $\mathrm{B} / \mathrm{C}$ ) by ice-stream flow but otherwise very similar in temperature and accumulation rate. There are numerous structural differences between the two cores, which are attributed to the effect of extreme strain in the ice stream. Integrating the difference between the two density profiles (in Alley and Bentley's figure 6), and dividing by the density of ice, one finds that the icestream effect has thinned the firn by $4 \mathrm{~m}$. A value six times larger than this is needed to account for the basal drag anomaly on Ice Stream B.

Special circumstances would be required to account for the anomalous drag result on the basis of contrasts in density. Perhaps, on Ice Stream B, Alley and Bentley penetrated a raft that had been only a little affected by the strain of the ice stream. Their two samples therefore would not display the full range in density contrast between ice-stream ice and inland ice. However, there are no data to support this suggestion.

\section{POSSIBLE EXPLANATIONS}

A number of potential interpretations are rejected in the section above. Remaining possibilities are that the form of the constitutive relation is wrong, that there are shortdistance variations in softness or crystal anistropy and that bridging effects are important.

\section{Constitutive relation}

Although the form of the constitutive relation is poorly established, the conventional form seems to have performed well in a qualitative sense in modeling most natural glacier flow (e.g. Hooke, 1981; Budd and Jacka, 1989; Van der Veen and Whillans, 1990). Ice Stream B is, however, special in that strain rates are very large for such cold ice, to the extent that there are strain shadows (Alley and Bentley, 1988). It could be that ice-stream flow is not accounted for by the conventional flow law.

Mechanisms that do not dominate at other sites may be more important in ice streams. For example, cyclic recrystallization (Jonas and Müller, 1969) may make the ice alternately hard and soft; also, normal stress effects (Man and Sun, 1987) or the role of the third invariant (Baker, 1987) may become important.

There is, furthermore, the possibility that the origin of the ice may play a role and, because the onset of streaming flow is so complex (Shabtaie and others, 1987; Whillans and others, 1987), it could be that different parts of the strain grid have different ice properties. This has been suggested by Frolich and Doake (1988) for Rutford Ice Stream. They proposed two distinct flow regimes that "interpenetrate". Perhaps ice that has passed through a shear margin is altered in a way to make its stiffness different. Perhaps, only some of the ice in the strain grid has been so altered. The result is that there are horizontal gradients in ice stiffness. Such gradients are not included in the calculation.

The contrary argument is that the strain-rate pattern seems to be approximately fixed with respect to the bed. If the anomalies were associated with the origin of the ice, then the anomalous pattern would be advected at the ice velocity. The two sets of strain-rate determinations differ by only 1 year, and this is insufficient to measure precisely the migration of the anomaly. However, the pattern is definitely not traveling as fast as the ice and could be fixed with respect to the bed. This suggests that something in the bed is causing the pattern.

\section{Short-distance gradients in crystal anistropy}

The ice crystals in the ice stream most probably are aligned and so have a strong crystal-orientation fabric. This anistropy makes the ice soft to certain stresses and hard to others. This alone cannot account for the problem but, if the anistropy changes from site to site, it would have an effect like that of horizontal variation in the rate factor in the constitutive relation, as discussed below.

Blankenship (1989) has conducted seismic measurements just to the south of the grid on Ice Stream B in order to determine the ice fabric. He obtained independent measures of the nature of the fabric symmetry and of the intensity of fabric development, as well as site-to-site variations. The simplest interpretation of the measurements is that the $c$-axis alignments lie within a cone whose principal axis is horizontal and along flow. The double angle of the cone is about $75^{\circ}$ but varies from site to site by about $10^{\circ}$.

Blankenship's survey covers a much smaller area than the full strain grid. It is possible that there are important fabric variations, in particular, at the up-glacier end of the grid where seismic studies were not conducted. Thus, it is fair to propose that there could be major spatial variations in ice fabric. To account for the present results, the spatial variations must travel at a slower speed than the ice. 


\section{Bridging effects}

In the simplified analysis conducted above, the vertical normal stress is taken to be equal to the lithostatic stress. Ordinarily, this is a reasonable approximation (Van der Veen and Whillans, 1989b) but the large spatial variation in basal drag calculated here (Fig. 3) raises the prospect that parts of the glacier may be resting more lightly on the bed than other parts. If so, there must be additional shear and normal horizontal stresses that distribute the weight of the glacier. Inclusion of these stresses alters the calculated basal drag. Without actually doing the calculation, it is difficult to foresee in which sense this effect works. As it turns out, it tends to diminish the spatial variability in basal drag.

The inclusion of bridging effects requires an extra term on the righthand side of Equation (1), which is often referred to as the " $T$ " term (Van der Veen and Whillans, 1989a, equation (31)):

$$
\frac{\partial}{\partial x} \int_{b}^{h} R_{z z} \mathrm{~d} z
$$

which is equal to (Van der Veen and Whillans, 1989a, equation (20)):

$$
\frac{\partial}{\partial x} \int_{b}^{h}\left[\frac{\partial}{\partial x} \int_{z}^{h} R_{x z} \mathrm{~d} \bar{z}+\frac{\partial}{\partial y} \int_{z}^{h} R_{y z} \mathrm{~d} \bar{z}\right] \mathrm{d} z
$$

in which $\bar{z}$ is a dummy variable. The effect of this term may be evaluated approximately by supposing that the shear stress varies linearly from zero at the surface to the value of basal drag $\left(\tau_{\mathrm{b} x}\right.$ or $\left.\tau_{\mathrm{b} y}\right)$ at the bed. With this approximation, the correction term becomes

$$
\frac{\partial^{2}}{\partial x^{2}}\left[\frac{1}{6} H^{2} \tau_{\mathrm{b} x}\right]+\frac{\partial^{2}}{\partial x \partial y}\left[\frac{1}{6} H^{2} \tau_{\mathrm{b} y}\right] .
$$

A more exact calculation would be possible if more surface velocities were available in the transverse direction (as done in Whillans and others (1989)). However, the strain grid is only three ranks wide, which means that the depth variation of terms involving transverse-direction gradients cannot be determined. Also, because the size of the grid only allows for calculation of the components of basal drag along the center line, transverse gradients in $\tau_{\mathrm{by}}$, as called for by the second term in Equation (11), cannot be determined. Therefore, as a start, this transverse gradient is neglected and only the first part of the correction in Equation (11) is evaluated.

Figure 3 also shows the result of this calculation (dotted curve in the lower panel). Although areas of negative drag persist, values of $\tau_{\mathrm{b} x}$ are now closer to zero than before.

Thus, inclusion of one part of bridging effects diminishes the negative basal drag. Should the contribution of the second term in Equation (11) be five times as large as that of the first term and vary in synchrony with it, the negative basal drag would be removed almost completely, except near the up-glacial end of the grid.

It is not known whether such a variation in $\tau_{b y}$ is realistic. It would imply some sort of grain to the bed. Although the bed could be fluted, it is not clear whether such flutes could lead to the necessary variation in $\tau_{b y}$. More extensive measurements of transverse strain-rate gradients would be needed to check this.

(The equations for bridging effects in Van der Veen and Whillans (1989a) contain an error, which is relatively unimportant. Interested persons may write to obtain the corrections. We are grateful to D. Bahr and R. Jacobel, and to J. Bolzan for discovering the error.)

\section{COMPARABLE RESULTS FROM ELSEWHERE}

Somewhat comparable results to those for Ice Stream B have been obtained by Frolich and Doake (1988) for Rutford Ice Stream. They used an along-flow integrated form of the force-budget equation used here, and so the $x$ derivative of their curve for "RF" in their figure 3 is basal drag. It is also negative at a few sites. Frolich and Doake did not discuss this result but their grid is only two stations wide and they must make an assumption about the value of $\partial\left(H R_{x y}\right) / \partial y$. That assumption could be in error and the calculated negative drags may be due to that. However, at face value, interpretation of the results from Rutford Ice Stream indicates rather similar problems to those encountered here.

Related results have also been obtained for Variegated Glacier, Alaska, during its surge (Raymond, 1987, fig. 8, bottom panel). At the point of maximum velocity, the basal drag is calculated to be negative, $-50 \mathrm{kPa}$. Raymond attributed this result to a failure of the flow law, especially at very low stresses. Our conclusions are in accord with those of Raymond.

There is further information on the force budget in the $y$-direction. That calculation predicts large variations in the $y$-component of basal drag, of both signs. In reality, the basal-drag vector is expected to be aligned with the ice velocity. Evidently, there are similar difficulties in accounting for the $y$-component of basal drag as for the $x$ component.

There are also difficulties in the interpretation of the strain-grid results for Dye 3 (Van der Veen and Whillans, 1990). However, the difficulties in interpretation there are of the opposite sense and much less severe. In effect, on Ice Stream B, measured surface strain-rate gradients are too negative to account for with conventional theory. At Dye 3 , they are too near zero for simple conventional theory. At Dye 3, the basal drag is positive everywhere and flow can be modeled approximately using the conventional flow law.

\section{DISGUSSION}

The patterns in strain rate and surface slope observed on Ice Streams B and C are unlike those normally expected. As modeled by Whillans and Johnsen (1983) and authors referenced therein, local variations in surface slope and strain rate can be accounted for by basal obstructions to flow. The obstruction can be locally large basal drag or locally large basal drag together with a reverse basal slope. Sliding speed is lower over the obstruction. The glacier has adjusted to the obstruction by developing a steeper surface slope and a down-flow gradient from more 
to less longitudinal stretching over the obstruction. This conventional model predicts a specific linkage between surface slope and longitudinal stretching. Such a linkage is not found on the ice streams.

A symptom of the unusual flow pattern is that basal drag under Ice Stream B is reversed in places. This is an untenable result. The data seem to be free of important errors. There must be some inadequacy in the physical model used for the glacier. If rather improbable effects, such as horizontal gradients in firn thickness, are put aside, the results point to incorrectly modeled strength variations for the ice.

According to this view, the measured strain rates reflect mainly ice strength and not stress. The results can be explained, if the ice at station B35 is stiffer to longitudinal tension than the ice at station B36, immediately up-glacier. This stiff ice is in the nose of the longitudinal ridge shown in Figure 2. The measured strain rate at the nose of the ridge, at station $\mathrm{B} 35$, is small but, if ice at that site is especially stiff, the associated longitudinal stress can be as large as elsewhere. In that case, there would be no special gradients in longitudinal force and no negative basal drag. The strength variations needed to account for the present results can be due to horizontal gradients in ice structure or to a more fundamental failing in the usual flow law for ice.

A very simple pattern in ice strength cannot account for the results. The simple pattern that is envisioned consists of vertical, planar sheets of foliation. Each folium contains ice with $c$-axes random or perpendicular to the folium, depending on whether the ice is isotropic or anisotropic. This model predicts that, where normal strain rates are small due to anistotropy, shear strain rates should be large and vice versa. Such a pattern is not observed and so the simple model does not apply. A more complex model with inclined lenses of folia is possible and may account for the results.

Non-radical adjustments to the form of the flow law are insufficient to account for the present result. The exponent, $n$, affects results through the effective strain rate. However, as noted above, that quantity varies slowly, and altering the value of the exponent has little impact. Similarly, a change in the value of the rate factor in the constitutive relation has mainly a scaling effect near station B35, and does not change the sign of the result.

An earlier explanation for local regions of stiffness is the raft suggestion, in which blocks of stiffer inland ice are advected with the ice stream (Whillans and others, 1987). However, the strain-rate pattern is moving more slowly than the ice flow and may be fixed with respect to the bed. If the stiffness variation were due to a raft, it would travel with the ice flow. The raft idea does not seem to account for the anomalies here.

Stiffness variations due to horizontal gradients in ice temperature are unlikely to be an explanation. Thermal diffusion is slow and ice-strength variations associated with temperature variations would be advected with the ice.

The strength variations in Ice Stream B must be due to ice structural variations that migrate against the ice flow, so that they are approximately fixed with respect to the bed. Possibilities include changes in crystal size or ice fabric that are caused by disturbances at the bed. Both are suspected to have major influences on ice strength (e.g. Kamb, 1972).

Data uncertainties are discounted. The most important measurement uncertainty is in surface slope. This directly affects driving stress and calculated basal drag by about $20 \mathrm{kPa}$. This is too small to account for the problem by itself. The rate factor is accurate to within a factor of about 2 (Hooke, 1981; Paterson and Budd, 1982). To eliminate the negative drag through data errors, the rate factor must be reduced to one-fifth of the value used and the maximum slope error must be invoked.

In view of the difficulty in accounting for the calculated negative basal drag, it is unclear how other features in the variation in drag on Ice Streams B and C should be interpreted. If Figure 3 is taken at face value, one would conclude that the drag under Ice Stream B is concentrated at "sticky spots" (stations B34 and B27). In fact, a test for the existence of such sticky spots was the original motive for the measurement program. As has been noted in the Introduction, sticky spots have been found for other glaciers but, in the model in which glacial flow is taken to be controled by mobile basal till (e.g. Alley and others, 1986), sticky spots are absent. The present result cannot be considered a test of the model of mobile basal till, because whatever leads to the untenable basal drag could also lead to large positive values that look like sticky spots.

\section{CONCLUSION}

Conventional theory does not apply to the detailed flow of Ice Stream B and probably also Ice Stream C. There are large horizontal variations in surface slope and strain rate that are difficult to explain. By elimination of other possibilities, the conclusion is reached that there are major horizontal gradients in ice strength, as deduced using the conventional flow law. The pattern of variation is moving less quickly than the ice and may be fixed with respect to the bed.

\section{ACKNOWLEDGEMENTS}

We thank R.B. Alley, C.S. M. Doake, C.F. Raymond and the referees for critical reviews, and numerous colleagues for helpful remarks. This research was supported by the U.S. National Science Foundation (grant DPP-8716447). This is Byrd Polar Research Center contribution No. 802.

\section{REFERENCES}

Alley, R. B. and C. R. Bentley. 1988. Ice-core analysis on the Siple Coast of West Antarctica. Ann. Glaciol., 11, 1-7.

Alley, R. B., D. D. Blankenship, C. R. Bentley and S. T. Rooney. 1986. Deformation of till beneath Ice Stream B, West Antarctica. Nature, 322(6074), 57-59.

Baker, R.W. 1987. Is the creep of ice really independent of the third deviatoric stress invariant? International Association of Hydrological Sciences Publication 170 (Symposium at Vancouver 1987 - The Physical Basis of Ice Sheet Modelling), 7-16.

Balise, M.J. and C.F. Raymond. 1985. Transfer of basal sliding variations to the surface of a linearly viscous glacier. F. Glaciol., 31(109), 308-318. 
Bindschadler, R. A., P. L. Vornberger, S. N. Stephenson, E. P. Roberts, S. Shabtaie and D.R. MacAyeal. 1988. Ice-shelf flow at the boundary of Crary Ice Rise, Antarctica. Ann. Glaciol., 11, 8-13.

Blankenship, D.D. 1989. Seismological investigations of a West Antarctic ice stream. (Ph.D. thesis, University of WisconsinMadison.)

Blankenship, D. D., C. R. Bentley, S. T. Rooney and R. B. Alley. 1986. Seismic measurements reveal a saturated porous layer beneath an active Antarctic ice stream. Nature, 322(6074), 54-57.

Boulton, G.S. and R.C.A. Hindmarsh. 1987. Sediment deformation beneath glaciers: rheology and geological consequences. F. Geophys. Res., 92(B9), 9059-9082.

Budd, W. F. and T. H. Jacka. 1989. A review of ice rheology for ice sheet modelling. Cold Reg. Sci. Technol., 16(2), 107-144.

Engelhardt, H., N. Humphrey, B. Kamb and M. Fahnestock. 1990. Physical conditions at the base of a fast moving Antarctic ice stream. Science, 248(4951), 57-59.

Frolich, R. M. and C.S. M. Doake. 1988. Relative importance of lateral and vertical shear on Rutford Ice Stream, Antarctica. Ann. Glaciol., 11, 19-22.

Hooke, R. LeB. 1981. Flow law for polycrystalline ice in glaciers: comparison of theoretical predictions, laboratory data, and field measurements. Rev. Geophys. Space Phys., 19(4), 664-672.

Hooke, R. LeB., P. Calla, P. Holmlund, M. Nilsson and A. Stroeven. 1989. A 3 year record of seasonal variations in surface velocity, Storglaciären, Sweden. F. Glaciol., 35(120), 235-247.

Johnson, A. M. 1970. Physical processes in geology. San Francisco, CA Freeman, Cooper and Co.

Jonas, J.J. and F. Müller. 1969. Deformation of ice under high internal shear stresses. Can. 7. Earth Sci., 6(4, Pt. 2), 963-968.

Kamb, B. 1972. Experimental recrystallization of ice under stress. In Heard, H. C., I. Y. Borg, N. L. Carter and C. B. Raleigh, eds. Flow and fracture of rocks. Washington, DC, American Geophysical Union, 211-241. (Geophysical Monograph Series, 16.)

MacAyeal, D. R., R.A. Bindschadler, S. Shabtaie, S. Stephenson and C. R. Bentley. 1987. Force, mass, and energy budgets of the Crary Ice Rise complex, Antarctica. F. Glaciol., 33(114), 218-230. Corrections: 35(119), 1989, 151-152.

McDonald, J. and I.M. Whillans. 1988. Comparison of results from Transit satellite tracking. Ann. Glaciol., 11, 83-88.
Man, C.-S. and Q-X. Sun. 1987. On the significance of normal stress effects in the flow of glaciers. F. Glaciol., 33(115), 268-273.

Paterson, W. S. B. and W.F. Budd. 1982. Flow parameters for ice sheet modelling. Cold Reg. Sci. Technol., 6(2), 175-177.

Raymond, C. F. 1987. How do glaciers surge? A review. F. Geophys. Res., 92(B9), 9121-9134.

Rose, K.E. 1979. Characteristics of ice flow in Marie Byrd Land, Antarctica. F. Glaciol., 24(90), 63-75.

Shabtaie, S. and C.R. Bentley. 1988. Ice-thickness map of the West Antarctic ice streams by radar sounding. Ann. Glaciol., 11, 126-136.

Shabtaie, S., I. M. Whillans and C. R. Bentley. 1987. The morphology of ice streams A, B, and C, West Antarctica, and their environs. $\mathcal{F}$. Geophys. Res., 92(B9), 8865-8883.

Thomas, R. H., S. N. Stephenson, R. A. Bindschadler, S. Shabtaie and C. R. Bentley. 1988. Thinning and grounding-line retreat on Ross Ice Shelf, Antarctica. Ann. Glaciol., 11, 165-172.

Van der Veen, C.J. and I. M. Whillans. 1989a. Force budget: I. Theory and numerical methods. F. Glaciol., 35(119), 53-60.

Van der Veen, C.J. and I.M. Whillans. 1989b. Force budget: II. Application to two-dimensional flow along Byrd Station Strain Network, Antarctica. F. Glaciol., 35(119), 61-67.

Van der Veen, C. J. and I. M. Whillans. 1990. Flow laws for glacier ice: comparison of numerical predictions and field measurements. F. Glaciol., 36(124), 324-339.

Vornberger, P. L. and I.M. Whillans. 1990. Crevasse deformation and examples from Ice Stream B, Antarctica. F. Glaciol., 122(36), 3-10.

Whillans, I. M. and R. Bindschadler. 1988. Mass balance of Ice Stream B. Ann. Glaciol., 11, 187-193.

Whillans, I. M. and S.J. Johnsen. 1983. Longitudinal variations in glacial flow: theory and test using data from the Byrd Station Strain Network, Antarctica. F. Glaciol., 29(101), 78-97.

Whillans, I. M., J. Bolzan and S. Shabtaie. 1987. Velocity of ice streams B and C, Antarctica. J. Geophys. Res., 92(B9), 8895-8902.

Whillans, I. M., Y. H. Chen, C.J. van der Veen and T.J. Hughes. 1989. Force budget: III. Application to three-dimensional flow of Byrd Glacier, Antarctica. F. Glaciol., 35(119), 68-80.

The accuracy of references in the text and in this list is the responsibility of the authors, to whom queries should be addressed. 